\title{
Risk factor screening for gestational diabetes mellitus based on the 2013 WHO criteria
}

\author{
Katrien Benhalima1, Paul Van Crombrugge², Carolien Moyson'1, Johan Verhaeghe ${ }^{3}$, Sofie Vandeginste 4

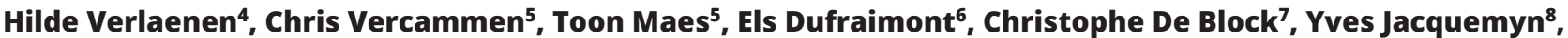 \\ Farah Mekahli', Katrien De Clippel ${ }^{10}$, Annick Van Den Bruel ${ }^{11}$, Anne Loccufier ${ }^{12}$, Annouschka Laenen ${ }^{13}$, \\ Caro Minschart ${ }^{1}$, Roland Devlieger ${ }^{3}$ and Chantal Mathieu' ${ }^{1}$
}

${ }^{1}$ Department of Endocrinology, University Hospital Gasthuisberg, KU Leuven, Leuven, Belgium, ${ }^{2}$ Department of Endocrinology, OLV Ziekenhuis Aalst-Asse-Ninove, Aalst, Belgium, 'Department of Obstetrics \& Gynecology, University Hospital Gasthuisberg, KU Leuven, Leuven, Belgium, ${ }^{4}$ Department of Obstetrics \& Gynecology, OLV Ziekenhuis Aalst-Asse-Ninove, Aalst, Belgium, ${ }^{5}$ Department of Endocrinology, Imelda Ziekenhuis, Bonheiden, Belgium, ${ }^{6}$ Department of Obstetrics \& Gynecology, Imelda Ziekenhuis, Bonheiden, Belgium, ${ }^{7}$ Department of Endocrinology-Diabetology-Metabolism, ${ }^{8}$ Department of Obstetrics \& Gynecology, Antwerp University Hospital, Edegem, Belgium, ${ }^{9}$ Department of Endocrinology, ${ }^{10}$ Department of Obstetrics \& Gynecology, Kliniek St-Jan Brussel, Brussel, Belgium, ${ }^{11}$ Department of Endocrinology, ${ }^{12}$ Department of Obstetrics \& Gynecology, AZ St Jan Brugge, Brugge, Belgium, and ${ }^{13}$ Center of Biostatics and Statistical Bioinformatics, KU Leuven, Leuven, Belgium

Correspondence should be addressed to K Benhalima Email

katrien.benhalima@ uzleuven.be

\begin{abstract}
Objective: Since many European countries use risk factor screening for gestational diabetes mellitus (GDM), we aimed to determine the performance of selective screening for GDM based on the 2013 WHO criteria.

Design and methods: Overall, 1811 women received universal screening with a $75 \mathrm{~g}$ oral glucose tolerance test (OGTT) with GDM in $12.5 \%$ ( $n=231$ ) women based on the 2013 WHO criteria. We retrospectively applied different European selective screening guidelines to this cohort and evaluated the performance of different clinical risk factors to screen for GDM.

Results: By retrospectively applying the English, Irish, French and Dutch guidelines for selective screening, respectively $28.5 \%(n=526), 49.7 \%(n=916), 48.5 \%(n=894)$ and 50.7\% $(n=935)$ had at least one risk factor, with GDM prevalence of respectively $6.5 \%(n=120), 7.9 \%(n=146), 8.0 \%(n=147)$ and $8.4 \%(n=154)$. Using maternal age $\geq 30$ and/or BMI $\geq 25$ for screening, positive rate was $69.9 \%(n=1288)$, GDM prevalence $10.2 \%(n=188)$, sensitivity $81.4 \%$ (Cl: $75.8-86.2 \%)$ and specificity $31.8 \%$ (Cl: 29.5-34.1\%). Adding other clinical risk factors did not improve detection. GDM women without risk factors had more neonatal hypoglycemia ( 14.4 vs $4.0 \%, P=0.001)$ and labor inductions (39.7 vs $25.9 \%$, $P=0.020$ ) than normal-glucose tolerant women, and less cesarean sections than GDM women with risk factors (13.8 vs $31.0 \%, P=0.010$ ).

Conclusions: By applying selective screening by European guidelines, about $50 \%$ of women would need an OGTT with the lowest number of missed cases (33\%) by the Dutch guidelines. Screening with age $\geq 30$ years and/or BMI $\geq 25$, reduced the number of missed cases to $18.6 \%$ but $70 \%$ would need an OGTT.
\end{abstract}

\section{Introduction}

Gestational diabetes mellitus (GDM) is defined as diabetes diagnosed in the second or third trimester of pregnancy provided that overt diabetes early in pregnancy has been excluded (1). Screening and treatment of GDM reduces the risk for pregnancy complications such as largefor-gestational age infants (LGAs) and preeclampsia $(2,3)$. Women with a history of GDM are at increased risk to develop type 2 diabetes (T2DM) later in life (4).

Published by Bioscientifica Ltd. 
Offspring of women with GDM have also a higher risk to become obese and develop T2DM later in life (5). The 'International Association of Diabetes and Pregnancy Study Groups' (IADPSG) and World Health Organization (WHO) recommend a universal one-step approach with the $75 \mathrm{~g}$ oral glucose tolerance test (OGTT) for screening of $\operatorname{GDM}(6,7)$. The IADPSG recommendation remains controversial due to the important increase in GDM prevalence, increased workload, the need for a fasting test and the risk for increased medicalization of care $(8,9,10)$. As a consequence, there is still a large variation in screening strategies for GDM used across Europe. A survey in 2015 demonstrated that the majority of European societies still recommended screening based on risk factors. Only a minority (37\%) recommended a universal one-step approach with a $75 \mathrm{~g}$ OGTT (11). Moreover, the risk factors used in European selective screening guidelines for GDM vary. More data are therefore needed on which clinical risk factors have the best detection rate for GDM when using selective screening. Data are also needed on whether pregnancy outcomes differ between GDM women with and without risk factors compared to normal glucosetolerant (NGT) women. We aimed therefore to determine the performance of selective screening based on different European guidelines compared to universal screening for GDM based on the 2013 WHO/IADPSG criteria from a large prospective cohort study. In addition, we evaluated the performance of different clinical risk factors to screen for GDM and evaluated pregnancy outcomes in GDM women stratified by risk factors compared to NGT women.

\section{Subjects and methods}

The cohort study was registered in ClinicalTrials.gov (NCT02036619). The study protocol was approved by the institutional review boards of all participating centers (B322201420693). Participants provided informed consent before inclusion in the study.

\section{Study design}

The Belgian Diabetes in Pregnancy study (BEDIP-N) was a multi-centric prospective cohort with 2006 women included before 14 weeks of pregnancy $(12,13,14)$. The overall objective of the BEDIP-N study was to evaluate the diagnostic accuracy of different screening strategies (universal one-step diagnostic approach with $75 \mathrm{~g}$ OGTT compared to a universal two-step screening strategy with a $50 \mathrm{~g}$ glucose challenge test (GCT) and selective screening based on risk factors) for GDM based on the 2013 WHO criteria. Participants were included between 6 and 14 weeks of pregnancy and were universally screened with a fasting plasma glucose to exclude prediabetes and diabetes (defined by the American Diabetes Association (ADA) criteria)) (15). Participants without prediabetes or diabetes in early pregnancy, received both a non-fasting GCT and $75 \mathrm{~g}$ 2-h OGTT between 24 and 28 weeks of pregnancy (12). Of all participants, 5.3\% (106) stopped with the study before 24 weeks of pregnancy, half of them due to a medical reason (14). During the study, participants and health care providers were blinded for result of the GCT. We have recently published the results on the accuracy of the GCT to screen for GDM based on the 2013 WHO criteria $(13,14)$. Women diagnosed with GDM were treated according to a standardized protocol in line with normal routine. (12) The ADA-recommended glycemic targets were used for the treatment of GDM (15). If targets were not achieved with lifestyle measures alone, treatment with insulin was initiated.

\section{Study assessments}

At first visit, baseline characteristics and risk factors for GDM such as maternal age, pre-pregnancy weight, ethnic background, history of smoking, family history of diabetes (a first- or second-degree relative with diabetes or a mother or sister with GDM), parity, history of polycystic ovarian syndrome (PCOS), GDM or impaired glucose intolerance and the obstetrical history were collected (12). Hypertension was defined as a systolic blood pressure (BP) $\geq 140 \mathrm{mmHg}$ and/or diastolic BP $\geq 90 \mathrm{mmHg}$, overweight as a BMI $\geq 25-29.9 \mathrm{~kg} / \mathrm{m}^{2}$ and obesity as a $\mathrm{BMI} \geq 30 \mathrm{~kg} / \mathrm{m}^{2}$. At first visit and at the time of the OGTT, anthropometric measurements were obtained (12). A $75 \mathrm{~g}$ OGTT (with measurement of glycaemia at 0,30,60 and $120 \mathrm{~min}$ ) was performed between 26 and 28 weeks of pregnancy. For the $75 \mathrm{~g}$ OGTT participants had to be fasting for at least $10 \mathrm{~h}$.

The following pregnancy outcome data were collected: gestational age, preeclampsia (de novo $\mathrm{BP}$ $\geq 140 / 90 \mathrm{mmHg}>20$ weeks with proteinuria or signs of end-organ dysfunction), gestational hypertension (de novo $\mathrm{BP} \geq 140 / 90 \mathrm{mmHg}>20$ weeks), type of labor and type of delivery with the indications, birth weight, macrosomia (>4 kg), birth weight $\geq 4.5 \mathrm{~kg}$, LGA defined as birth weight $>90$ percentile according to standardized Flemish birth charts adjusted for sex of the baby and parity (16), small for gestational age (SGA) defined as birth weight $<10$ percentile according to standardized Flemish birth charts adjusted for sex of the baby and parity (16), preterm 
delivery (<37 completed weeks), 10 min Apgar score, shoulder dystocia, neonatal respiratory distress syndrome, neonatal jaundice, congenital anomalies, neonatal hypoglycemia (defined as glycemia $<2.2 \mathrm{mmol} / \mathrm{L}$ ) and admission on the neonatal intensive care unit (NICU) (12). To compare pregnancy outcomes in GDM women stratified by risk factors compared to NGT women, GDM women without risk factors were defined as BMI $<25 \mathrm{~kg} /$ $\mathrm{m}^{2}$, maternal age $<35$ years, no history of a macrosomic baby $(>4 \mathrm{~kg})$, no history of a first-degree relative with diabetes, a Caucasian origin, no previous history of GDM, PCOS or impaired glucose tolerance.

\section{Analyses of the performance of selective screening for GDM}

We analyzed the prevalence of GDM and the number of missed cases with selective screening compared to universal screening with $75 \mathrm{~g}$ OGTT by retrospectively applying selective screening to our cohort according to the following European guidelines: the National Institute for Health and Clinical Excellence (NICE) guidelines from 2015, the Irish guidelines from 2010, the French guidelines from 2010 and the Dutch guidelines from 2010 (17, 18, $19,20)$ (Table 1 ). The positive rate was defined as the number of pregnant women ( $\%$ and $n$ ) with at least one risk factor who would receive an OGTT to screen for GDM according to the different guidelines. The lowest number of missed cases with GDM was defined as the number of theoretically missed cases with GDM when using selective screening according to the different guidelines compared to universal screening with a $75 \mathrm{~g}$ OGTT (GDM by universal screening but no risk factors according to each guideline respectively). We also evaluated the performance of selective screening according to the former ADA guidelines (before the endorsement of universal screening

Table 1 Overview of the different guidelines for selective screening for GDM.

\begin{tabular}{l} 
NICE \\
\hline BMI $\geq 30$ \\
Family history of diabetes \\
$\quad$ (first-degree relative with \\
diabetes) \\
Previous macrosomic baby \\
$\geq 4.5 \mathrm{~kg}$ \\
Previous GDM \\
Minority ethnic family origin \\
with a high prevalence of \\
diabetes (non-Caucasian)
\end{tabular}

$$
\begin{aligned}
& \text { PCOS } \\
& \text { History of unexplained } \\
& \text { miscarriage }
\end{aligned}
$$

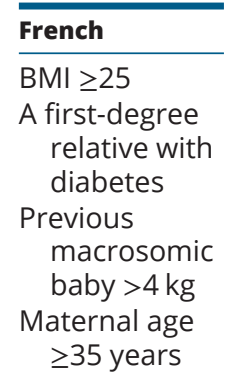
relative with diabetes

Previous macrosomic baby $>4 \mathrm{~kg}$ Maternal age $\geq 35$ years

Non-Caucasian (ethnicity associated with a high prevalence of diabetes)
A first-degree relative with diabetes

Previous macrosomic baby $>4.5 \mathrm{~kg}$

Previous GDM

Non-Caucasian (ethnicity Non-Caucasian (ethnicity associated with a high prevalence of diabetes)

PCOS

History of unexplained miscarriage

\section{ADA \\ $\mathrm{BMI} \geq 25+1$ risk factor \\ A first-degree relative with diabetes \\ Previous macrosomic baby $>4.5 \mathrm{~kg}$} associated with a high prevalence of diabetes)

PCOS
Low HDL cholesterol ( $<1.0 \mathrm{mmol} / \mathrm{L})$ and high Triglycerides (>1.7 mmol/L)
History of impaired glucose tolerance
*History of cardiovascular disease
Hypertension (BP systolic $\geq 140$ and/or diastolic $\geq 90$ )

Polyhydramnios and/or macrosomia in existing pregnancy

*Current glucosuria

**Women on long-term steroids

*Variables not available in the BEDIP-N database; **this was an exclusion criterion in the BEDIP-N study.

ADA, American Diabetes Association; BMI, body mass index ( $\left.\mathrm{kg} / \mathrm{m}^{2}\right)$; BP, blood pressure; GDM, gestational diabetes mellitus; NICE, the National Institute for Health and Clinical Excellence guidelines; PCOS, polycystic ovarian syndrome. 
in 2010) (21). In addition, we analyzed the detection rate of GDM across different thresholds for maternal age and BMI with and without the addition of other clinical risk factors (first-degree family history of diabetes, history of GDM, non-Caucasian origin and a history of a macrosomic baby $\geq 4.5 \mathrm{~kg}$ ).

\section{Statistical analysis}

Logistic regression models were used for data analysis with GDM as a binary response variable and maternal age or BMI as continuous predictors. The discriminative power of the predictors for GDM is presented by receiveroperating (ROC) curves and estimated as the area under the curve (AUC) with 95\% CI. The AUC ranges between 0.5 (discrimination no better than chance) and 1 (perfect discrimination). As a potential measure to evaluate the optimal cut-off value of both predictors the maximum Youden index was determined, giving equal importance to sensitivity and specificity. In addition, we evaluated the diagnostic accuracy (the sensitivity, specificity, positive and negative likelihood ratio, with 95\% CIs) across a wide range of different cut-offs for maternal age and BMI with and without the addition of other clinical risk factors (binary or dichotomized variables).

Comparisons of pregnancy outcomes between women with GDM, with and without risk factors and with the NGT group, were performed using Mann-Whitney $U$ test for continuous variables, and chi-square test for categorical variables or Fisher exact test for binary variables with small $(<5)$ cell frequencies. A $P$ value $<0.05$ (two-tailed) was considered significant. Analyses were performed by statistician A. Laenen using SAS software (version 9.4).

\section{Results}

\section{Study participants}

Of all participants, 1841 (91.8\%) received a $75 \mathrm{~g}$ OGTT between 24 and 28 weeks of pregnancy. Based on a universal screening strategy with the $75 \mathrm{~g}$ OGTT and 2013 WHO criteria of the whole cohort, the prevalence of GDM was $12.5 \%$ (231).

\section{The performance of the European selective screening guidelines for GDM}

When we applied the NICE, Irish, French, Dutch and ADA guidelines, respectively $28.5 \%(n=526), 49.7 \%(n=916)$, $48.5 \%(n=894), 50.7 \%(n=935)$ and $49.5 \%(n=913)$ of all women had at least one risk factor and would have received an OGTT, leading to a GDM prevalence of respectively $6.5 \%(n=120), 7.9 \%(n=146), 8.0 \%(n=147)$, $8.4 \%(n=154)$ and $8.4 \%(n=155)$ (Tables 1 and 2$)$. Of all women with GDM (231), the diagnosis would be missed when NICE, Irish, French, Dutch and ADA guidelines were applied in respectively $48 \%(n=111), 36.8 \%(n=85)$, $36.4 \%(n=84), 33.3 \%(n=77)$ and $32.9 \%(n=76)$ of all women with GDM (Table 2).

\section{The performance of screening based on clinical risk factors}

The maximum Youden index (0.134) was seen at a maternal age $\geq 30$ years, with a sensitivity of $72.7 \%$ and specificity of $40.7 \%$. The maximum Youden index (0.159) for maternal BMI in early pregnancy was seen at a BMI $\geq 25 \mathrm{~kg} / \mathrm{m}^{2}$, with a sensitivity of $48.4 \%$ and specificity of $67.5 \%$. The AUC on the ROC curve for maternal age to predict GDM was 0.58 (95\% CI: 0.54-0.63) and the AUC for maternal BMI in early pregnancy was 0.61 (95\% CI: 0.57-0.65) (Fig. 1). Using these cut-offs for screening, the positive rate was $69.9 \%(n=1288)$, GDM prevalence $10.2 \% \quad(n=188), 18.6 \% \quad(n=43)$ of women with GDM would be missed, sensitivity was $81.4 \%$ (CI: 75.8-86.2\%) and specificity 31.8\% (CI: 29.5-34.1\%) (Table 3). By adding other clinical risk factors such as a first-degree family history of diabetes, a previous history of GDM, non-Caucasian origin and a history of a macrosomic baby, the positive rate was $70.5 \%(n=1300)$, GDM prevalence was $10.5 \%(n=193), 16.4 \%(n=38)$ of women with GDM

Table 2 The numbers diagnosed with GDM based on the different screening guidelines.

\begin{tabular}{|c|c|c|c|c|c|c|}
\hline & Universal & NICE & Irish & French & Dutch & ADA \\
\hline$\%(n)$ OGTT needed & 100 (1843) & $28.5(526)$ & 49.7 (916) & 48.5 (894) & 50.7 (935) & 49.5 (913) \\
\hline$\%(n)$ GDM & $12.5(231)$ & $6.5(120)$ & $7.9(146)$ & $8.0(147)$ & $8.4(154)$ & $8.4(155)$ \\
\hline $\begin{array}{l}\%(n) \text { with GDM, theoretically missed (GDM by } \\
\text { universal screening but no risk factors according } \\
\text { to each guideline) }\end{array}$ & 0 & $48.0(111)$ & $36.8(85)$ & $36.4(84)$ & 33.3 (77) & $32.9(76)$ \\
\hline
\end{tabular}



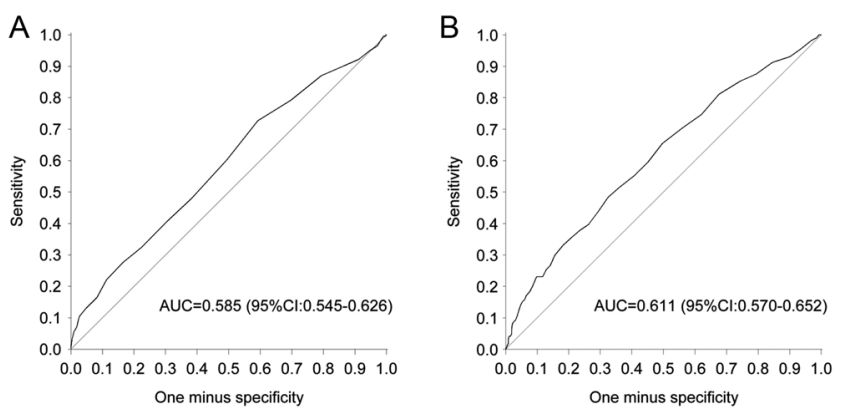

\section{Figure 1}

( $A$ and $B$ ) ROC curves for maternal age and $\mathrm{BMI}$ in early pregnancy as a predictor for GDM. AUC, area under the curve; ROC, receiver-operating curve. (A) ROC curve for maternal age; (B) ROC curve for BMI.

would be missed, sensitivity was $83.5 \%$ (CI: 78.1-88.1\%) and specificity 31.4\% (CI: 29.1-33.7\%) (Table 3).

\section{Pregnancy outcomes in GDM stratified by risk factors compared to NGT women}

Of all women with GDM, 25.6\% $(n=59)$ had no risk factors (Table 4). Compared to NGT women, GDM women without risk factors had significantly more often labor inductions (39.7.1 vs $25.9 \%, P=0.020$ ) and significantly more often neonatal hypoglycemia (14.4 vs $4.0 \%, P=0.001)$ (Table 4$)$. Compared to GDM women with risk factors, GDM women without risk factors had similar pregnancy outcomes except for less cesarean sections (14.3 vs 30.6\%, $P=0.016$ ). Compared to NGT women, GDM women with risk factors had more labor inductions (34.5 vs $25.9 \%, P=0.016)$, more cesarean sections (planned and emergency cesarean sections combined: 31.0 vs $20.2 \%, P=0.001$; emergency cesarean sections: 16.4 vs $10.0 \%, P=0.013)$, more often neonatal hypoglycemia (14.6 vs $4.0 \%, P<0.001)$ and more NICU admissions (14.6 vs 9.6\%, $P=0.037$ ) (Table 4). The most common indication for labor inductions was maternal pathology, but without large differences in preexisting pathologies or complications between GDM and NGT women, suggesting a diagnosis of GDM as main indication for the labor inductions (Table 4).

\section{Discussion}

Screening practices for GDM vary substantially across Europe (11). The IADPSG/2013 WHO universal onestep screening strategy for GDM has not yet been implemented in many European countries due to the increased workload and the limited data on the costeffectiveness of the IADPSG one-step diagnostic approach (8). Selective screening based on risk factors is therefore still recommended in many European countries as an alternative to limit health care expenses and limit the number of OGTTs $(11,22)$. However, the risk factors used in European selective screening guidelines for GDM vary. Our study aimed therefore to evaluate which clinical risk factors have the best detection rate for GDM when using selective screening. We show that by applying selective screening by most European guidelines, about 50\% of women would need an OGTT with the lowest number of missed cases (33\%) by the Dutch guidelines. Our study is in line with previous studies showing that selective screening would lead to missing one-third of women with $\operatorname{GDM}(23,24,25)$. Applying selective screening guidelines for GDM to a large pregnant cohort from Ireland showed that the former ADA guidelines would result in the lowest number $(5 \%)$ of missed cases compared to the Irish (16\%) and the NICE guidelines (20\%) (26). This is less than in our study, showing that by applying the NICE guidelines, nearly half of all women with GDM would be missed. However, the Irish study did not evaluate the performance of selective screening according to the French and Dutch guidelines.

By using easy available clinical risk factors such as maternal age and BMI, selective screening guidelines for GDM could be simplified. We demonstrate that the most sensitive and specific cut-offs for maternal age and BMI in our population to screen for GDM, are maternal age $\geq 30$ years and BMI in early pregnancy $\geq 25 \mathrm{~kg}$ / $\mathrm{m}^{2}$. Screening by these risk factors, $70 \%$ of all women would need an OGTT and the number of missed cases would be reduced to $18.6 \%$. Adding other clinical risk factors did not significantly improve the detection rate, indicating that a simple approach of offering an OGTT to women $\geq 30$ years and/or with a BMI $\geq 25 \mathrm{~kg} / \mathrm{m}^{2}$ might be as good as more complex risk prediction models. This is supported by a meta-analysis showing that more complex selective screening models (by combinations of risk factors or prediction models or scores) did not improve the detection rate compared to strategies that simply use maternal age and BMI to screen for GDM (27). We have previously demonstrated that a modified twostep screening strategy with a GCT and several clinical risk factors (BMI $\geq 30 \mathrm{~kg} / \mathrm{m}^{2}$, non-Caucasian origin and previous history of GDM) reduced the number of women missed with GDM to $17 \%$ while avoiding an OGTT in about $50 \%$ of women (14). We show now that the most appropriate clinical risk factors to determine which 


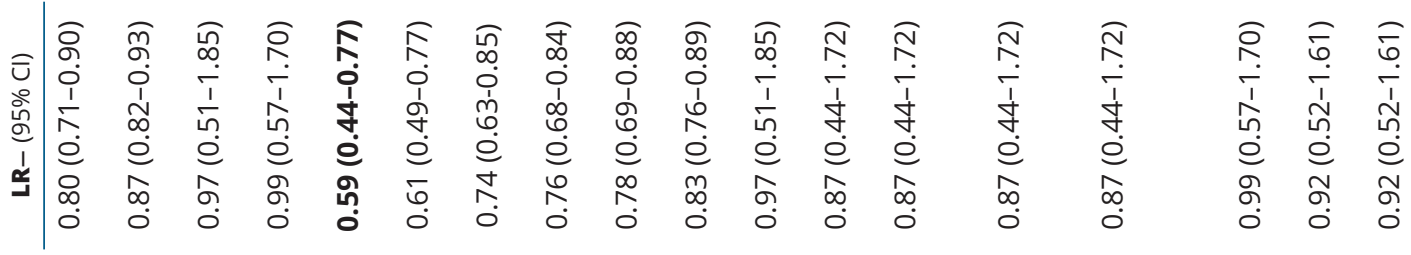

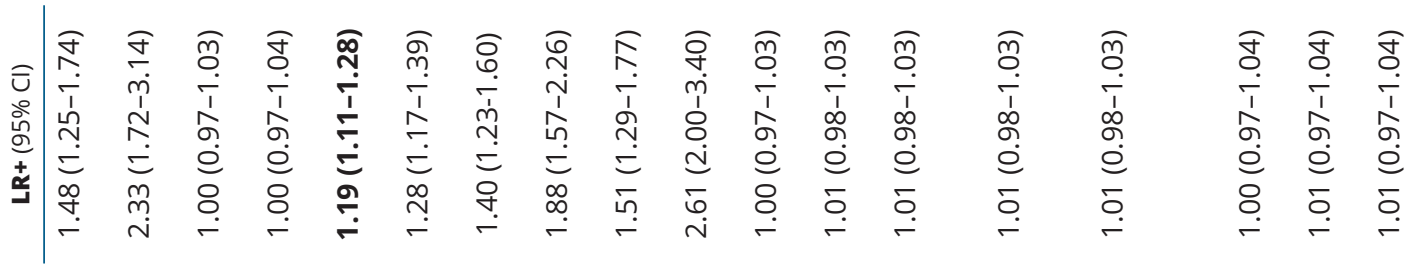

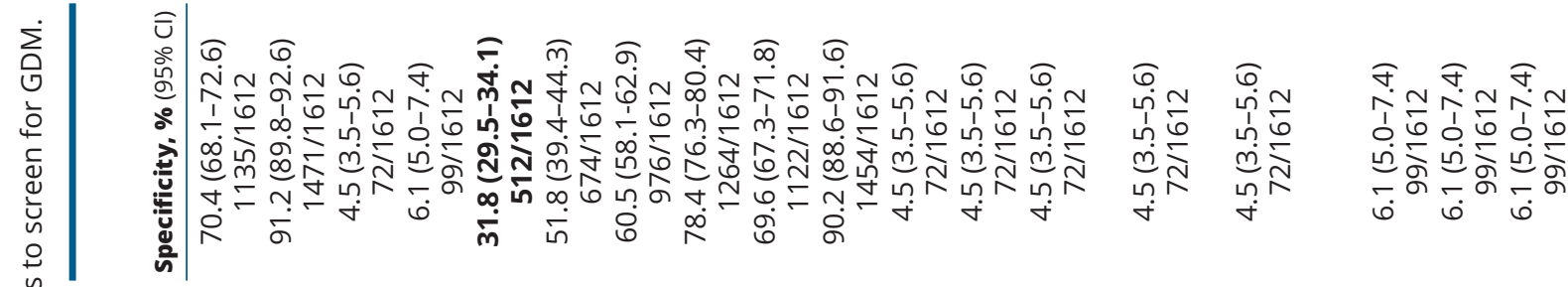



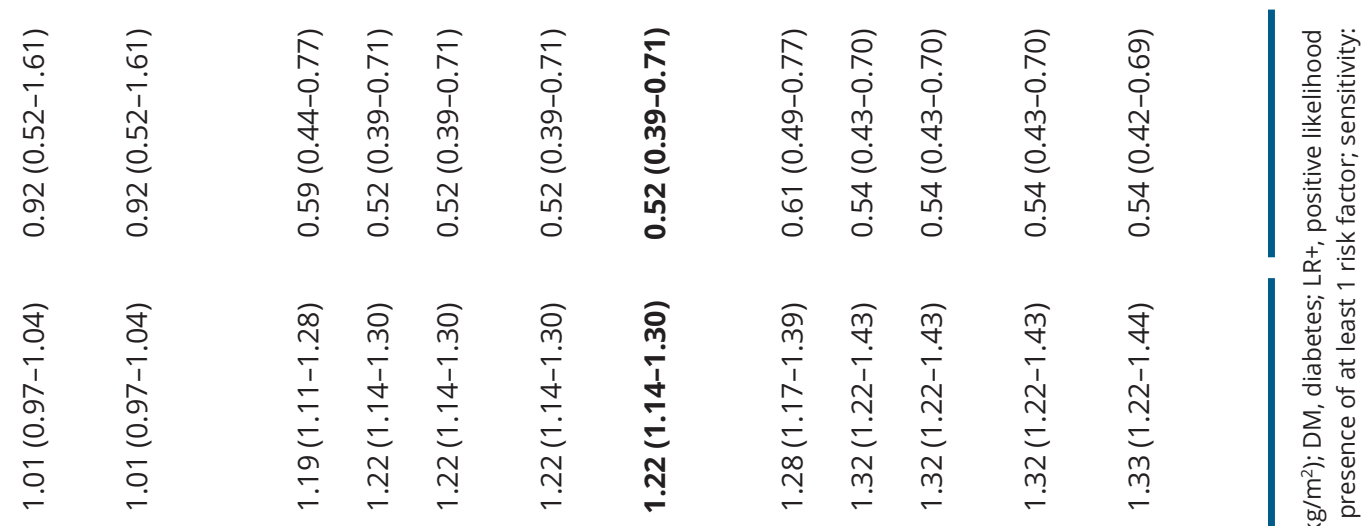

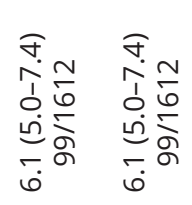
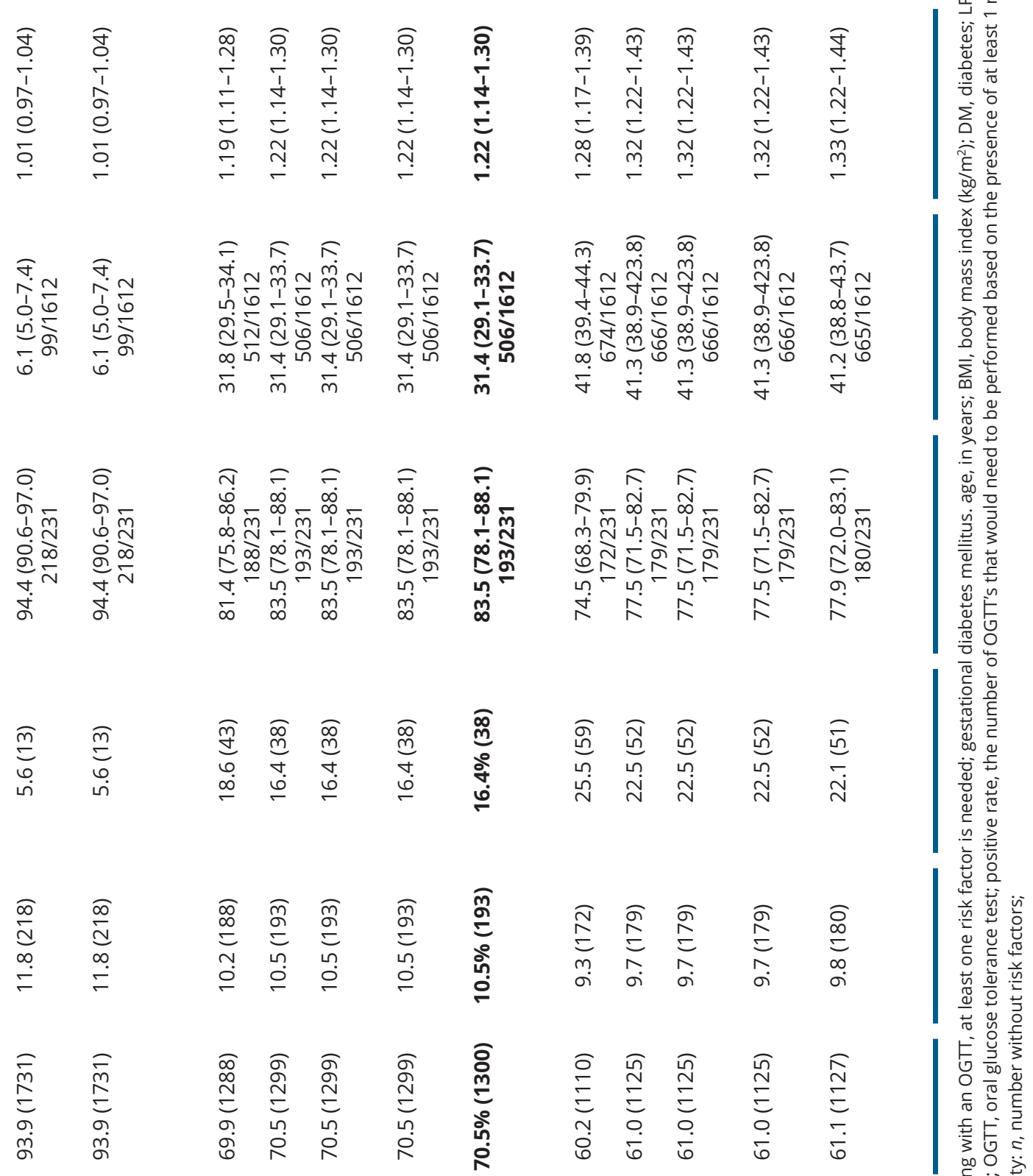

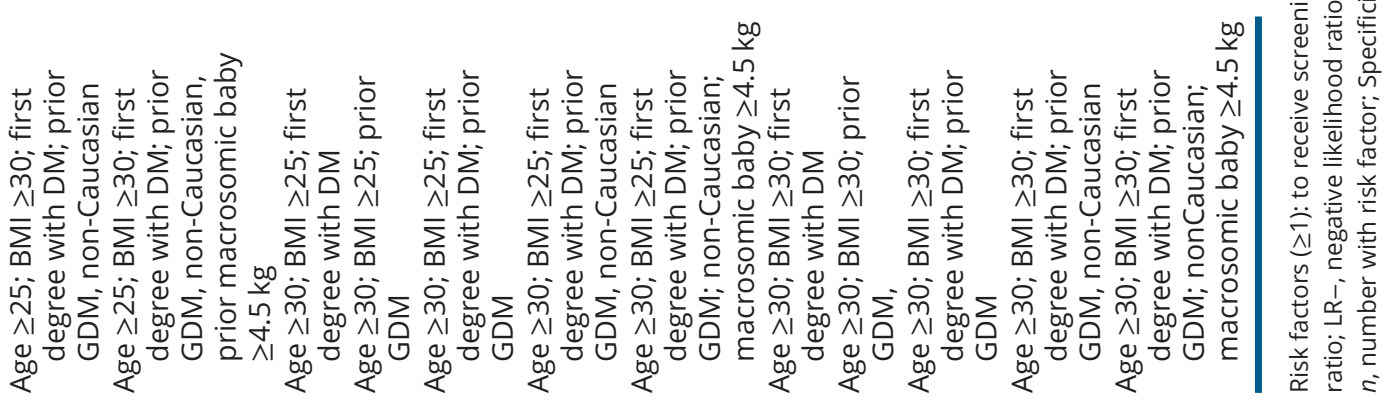


Table 4 Pregnancy outcomes in GDM women stratified by risk factors compared to normal glucose tolerant women.

(⿸丆口

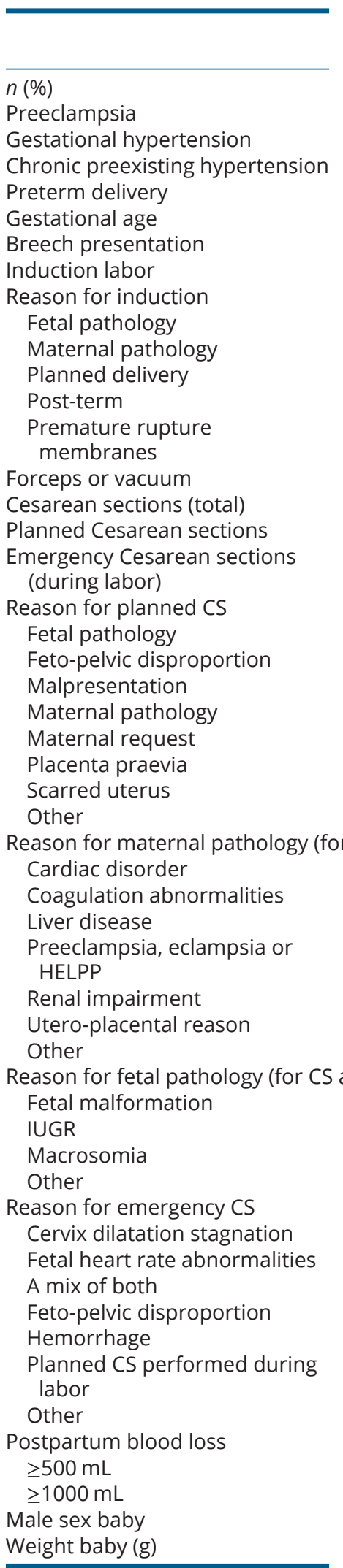

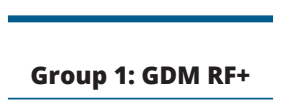

$172(74.4)$

$1.2 \%(2 / 171)$

$5.3 \%(9 / 171)$

$2.9 \%(5 / 171)$

$8.2 \%(14 / 171)$

$38.8 \pm 1.5$

$2.9 \%(5 / 171)$

$34.5 \%(59 / 171)$

$3.6 \%(2 / 56)$

$75.0 \%(42 / 56)$

$7.1 \%(4 / 56)$

$8.9 \%(5 / 56)$

$5.4 \%(3 / 56)$

$10.5 \%(18 / 171)$

$31.0 \%(53 / 171)$

$14.6 \%(25 / 171)$

$16.4 \%(28 / 171)$

$4.0 \%(1 / 25)$

$0 \%(0 / 25)$

$20.0 \%(5 / 25)$

$8.0 \%(2 / 25)$

$0 \%(0 / 25)$

$4.0 \%(1 / 25)$

$44.0 \%(11 / 25)$

20.0\% (5/25)

and induction)

$2.1 \%(1 / 47)$

$0 \%(0 / 47)$

$0 \%(0 / 47)$

$10.6 \%(5 / 47)$

$0 \%(0 / 47)$

$0 \%(0 / 47)$

$87.2 \%(41 / 47)$

d induction)

$20.0 \%(1 / 5)$

$0 \%(0 / 5)$

$40.0 \%(2 / 5)$

$40.0 \%(2 / 5)$

$33.3 \%(9 / 27)$

$29.6 \%(8 / 27)$

$0 \%(0 / 27)$

$11.1 \%(3 / 27)$

$3.7 \%(1 / 27)$

$3.7 \%(1 / 27)$

$18.5 \%(5 / 27)$

$21.6 \%(37 / 171)$

$2.9 \%(5 / 171)$

$52.9 \%(90 / 170)$

$3347.7 \pm 487.2$

\begin{tabular}{c}
\hline Group 2: GDM RF- \\
\hline $59(25.6)$ \\
$1.7 \%(1 / 58)$ \\
$0 \%(0 / 58)$ \\
$0 \%(0 / 58)$ \\
$5.2 \%(3 / 58)$
\end{tabular}

$39.2 \pm 1.3$

$5.2 \%(3 / 58)$

$39.7 \%(23 / 58)$

$4.3 \%(1 / 23)$

$65.2 \%(15 / 23)$

$8.7 \%(2 / 23)$

$17.4 \%(4 / 23)$

$4.3 \%(1 / 23)$

$15.5 \%(9 / 58)$

$13.8 \%(8 / 58)$

$6.9 \%(4 / 58)$

$6.9 \%(4 / 58)$

$25.0 \%(1 / 4)$

$25.00 \%(1 / 4)$

$50.0 \%(2 / 4)$

$0 \%(0 / 4)$

$0 \%(0 / 4)$

$0 \%(0 / 4)$

$0 \%(0 / 4)$

$0 \%(0 / 4)$

$0 \%(0 / 15)$

$6.7 \%(1 / 15)$

$0 \%(0 / 15)$

$0 \%(0 / 15)$

$0 \%(0 / 15)$

$0 \%(0 / 15)$

$93.3 \%(14 / 15)$

$0 \%(0 / 3)$

$33.3 \%(1 / 3)$

$66.8 \%(2 / 3)$

$0 \%(0 / 0)$

$33.3 \%(1 / 3)$

$33.3 \%(1 / 3)$

$0 \%(0 / 3)$

$0 \%(0 / 3)$

$0 \%(0 / 3)$

$0 \%(0 / 3)$

\section{$33.3 \%(1 / 3)$}

$17.2 \%(10 / 58)$

$5.2 \%(3 / 58)$

$48.3 \%(28 / 58)$

$3269.1 \pm 439.6$

\begin{tabular}{c}
\hline Group 3: NGT \\
\hline 1612 \\
$1.8 \%(29 / 1608)$ \\
$4.2 \%(68 / 1608)$ \\
$0.7 \%(11 / 1605)$ \\
$5.4 \%(86 / 1601)$ \\
$39.3 \pm 1.6$ \\
$5.7 \%(92 / 1605)$ \\
$25.9 \%(416 / 1605)$
\end{tabular}

$13.5 \%(56 / 416)$

$25.2 \%(105 / 416)$

$13.2 \%(55 / 416)$

$35.6 \%(148 / 416)$

$12.5 \%(52 / 416)$

$12.3 \%(198 / 1603)$

$20.2 \%(324 / 1603)$

$10.2 \%(164 / 1603)$

$10.0 \%(160 / 1603)$

0.308

0.010

0.170

0.082

0.488

0.001

0.473

1.000
0.116

0.76

0.551

0.014

0.160

$<0.001$

0.155

0.016

$<0.001$

0.089

0.013

0.230

0.047

0.078

0.652

$6.6 \%(10 / 151)$

$4.0 \%(6 / 151)$

$39.1 \%(59 / 151)$

$9.9 \%(15 / 151)$

$2.6 \%(4 / 151)$

$4.6 \%(7 / 151)$

$15.9 \%(24 / 151)$

$17.2 \%(26 / 151)$

$0 \%(0 / 122)$

$3.3 \%(4 / 122)$

$3.3 \%(4 / 122)$

$25.4 \%(31 / 122)$

$0.8 \%(1 / 122)$

$4.1 \%(5 / 122)$

$63.1 \%(77 / 122)$

$6.8 \%(5 / 73)$

$23.3 \%(17 / 73)$

$26.0 \%(19 / 73)$

$43.8 \%(32 / 73)$

$25.3 \%(40 / 158)$

$31.0 \%(49 / 158)$

$3.2 \%(5 / 158)$

$13.9 \%(22 / 158)$

$0.6 \%(1 / 158)$

$6.3 \%(10 / 158)$

$19.6 \%(31 / 158)$

$20.7 \%(327 / 1583)$

$2.5 \%(39 / 1583)$

49.7\% (797/1602)

$3397.9 \pm 509.9$
0.292

0.462

0.339

0.973

0.696

0.982

0.503

0.809

0.297

\begin{tabular}{lll}
0.539 & 0.429 & 0.825 \\
0.113 & 0.233 & 0.016 \\
\hline & (Continued)
\end{tabular}


Table 4 Continued.

\begin{tabular}{l}
\hline \\
\hline Length baby (cm) \\
Head circumference baby (cm) \\
Macrosomia ( $>4 \mathrm{~kg}$ ) \\
Weight baby $\geq 4.5 \mathrm{~kg}$ \\
LGA \\
SGA \\
Apgar 10 min $<7$ \\
Shoulder dystocia \\
Birth trauma (total) \\
Brain hematoma \\
Clavicular or humerus fracture \\
Perinatal asphyxia \\
Plexus brachialis palsy \\
Congenital anomaly (total) \\
Respiratory distress syndrome \\
Neonatal hypoglycemia \\
( $\leq 2.2$ mmol/l) \\
Neonatal jaundice \\
NICU admission \\
Days on NICU
\end{tabular}

\begin{tabular}{|c|c|}
\hline Group 1: GDM RF+ & Group 2: GDM RF- \\
\hline $50.2 \pm 2.1$ & $49.8 \pm 2.1$ \\
\hline $34.4 \pm 1.6$ & $34.1 \pm 1.5$ \\
\hline $6.5 \%(11 / 170)$ & $8.6 \%(5 / 58)$ \\
\hline $0.6 \%(1 / 171)$ & $0 \%(0 / 58)$ \\
\hline $12.3 \%(21 / 171)$ & $12.1 \%(7 / 58)$ \\
\hline $5.3 \%(9 / 171)$ & $3.4 \%(2 / 58)$ \\
\hline $0.6 \%(1 / 170)$ & $0 \%(0 / 58)$ \\
\hline $1.2 \%(2 / 171)$ & $0 \%(0 / 58)$ \\
\hline $0 \%(0 / 169)$ & $0 \%(0 / 58)$ \\
\hline $0.6 \%(1 / 169)$ & $0 \%(0 / 58)$ \\
\hline $0 \%(0 / 169)$ & $0 \%(0 / 58)$ \\
\hline $0 \%(0 / 169)$ & $0 \%(0 / 58)$ \\
\hline $5.3 \%(9 / 171)$ & $3.5 \%(2 / 57)$ \\
\hline $0.6 \%(1 / 171)$ & $1.7 \%(1 / 58)$ \\
\hline $14.4 \%(22 / 153)$ & $13.7 \%(7 / 51)$ \\
\hline $16.4 \%(19 / 116)$ & $13.5 \%(5 / 37)$ \\
\hline $14.6 \%(25 / 171)$ & $12.1 \%(7 / 58)$ \\
\hline $7.9 \pm 8.5$ & $3.8 \pm 3.7$ \\
\hline
\end{tabular}

\begin{tabular}{|c|c|c|c|}
\hline \multirow[b]{2}{*}{ Group 3: NGT } & \multicolumn{3}{|c|}{$P$ value } \\
\hline & 1 vs 2 & 1 vs 3 & 2 vs 3 \\
\hline $50.5 \pm 2.6$ & 0.145 & 0.075 & 0.009 \\
\hline $34.4 \pm 1.8$ & 0.198 & 0.585 & 0.231 \\
\hline $9.4 \%(151 / 1600)$ & 0.580 & 0.202 & 0.834 \\
\hline $1.3 \%(21 / 1602)$ & 1.000 & 0.716 & 1.000 \\
\hline $12.9 \%(206 / 1601)$ & 0.966 & 0.827 & 0.858 \\
\hline $5.1 \%(81 / 1598)$ & 0.734 & 0.855 & 1.000 \\
\hline $0.9 \%(15 / 1597)$ & 1.000 & 1.000 & 1.000 \\
\hline \multirow[t]{2}{*}{$1.1 \%(18 / 1598)$} & 1.000 & 1.000 & 1.000 \\
\hline & 0.557 & 0.303 & 0.982 \\
\hline \multicolumn{4}{|l|}{$0.2 \%(3 / 1603)$} \\
\hline \multicolumn{4}{|l|}{$0.1 \%(1 / 1603)$} \\
\hline \multicolumn{4}{|l|}{$0.4 \%(6 / 1603)$} \\
\hline \multicolumn{4}{|l|}{$0.1 \%(1 / 1603)$} \\
\hline $4.3 \%(68 / 1593)$ & 0.735 & 0.553 & 1.000 \\
\hline $0.9 \%(15 / 1594$ & 0.443 & 1.000 & 0.437 \\
\hline $4.0 \%(41 / 1023)$ & 0.908 & $<0.001$ & 0.001 \\
\hline $18.9 \%(216 / 1141)$ & 0.676 & 0.502 & 0.406 \\
\hline $9.6 \%(153 / 1597)$ & 0.628 & 0.037 & 0.529 \\
\hline $8.4 \pm 14.0$ & 0.369 & 0.945 & 0.382 \\
\hline
\end{tabular}

CS, cesarean section; GDM, gestational diabetes mellitus; NGT, normal glucose tolerant women; NICU, neonatal intensive care unit; RF+, with risk factors; $\mathrm{RF}-$, without risk factors (BMI $<25 \mathrm{~kg} / \mathrm{m}^{2}$, maternal age $<35$ years, no history of a macrosomic baby ( $>4 \mathrm{~kg}$ ), no history of a first-degree relative with diabetes, a Caucasian origin, no history of polycystic ovarian syndrome, GDM or impaired glucose tolerance).

women should receive an OGTT when using selective screening differ from the most appropriate clinical risk factors when using a modified two-step screening strategy with GCT. This difference is related to the characteristics of women with GDM that would be missed when using a GCT with a threshold $\geq 7.2 \mathrm{mmol} / \mathrm{L}$ (14).

Using an efficient screening strategy with clinical risk factors, might identify a GDM group at high risk for adverse pregnancy outcomes while universal screening might identify more women with GDM at low risk with less clinical significance (28). However, other studies have shown similar adverse pregnancy outcomes among young, lean women with $\operatorname{GDM}(29,30)$. We demonstrate that despite treatment, GDM women without risk factors had still higher rates of labor inductions and neonatal hypoglycemia than NGT women. In addition, women with GDM without risk factors had a non-significantly higher rate of instrumental delivery than NGT women but a significantly lower rate of cesarean sections. The pregnancy outcomes in GDM women without risk factors were better than in GDM women with risk factors. GDM women with risk factors had higher rates of cesarean sections, labor inductions, neonatal hypoglycemia and NICU admissions than NGT women. The differences in pregnancy outcomes between both GDM groups is probably mainly driven by the presence of risk factors such as an increased BMI which is an established independent risk factor for adverse pregnancy outcomes (9). However, the increased rates of labor inductions seem to be largely driven by the label of ' $G D M$ ' rather than a clear clinical indication while the increased rate of cesarean sections was driven by an increase in emergency cesarean sections. This highlights the need for appropriate education on the management of GDM, especially in the face of the increased prevalence of GDM when using a universal onestep screening strategy identifying many women with mild forms of GDM.

By diagnosing GDM, a group of women at high risk to develop T2DM and cardiovascular disease later in life is identified $(4,31)$. GDM women diagnosed by a universal one-step screening strategy with 2013 WHO criteria might have a lower risk for glucose intolerance in early postpartum than women diagnosed by a twostep screening strategy $(32,33,34)$. A universal one-step screening strategy might identify milder forms of GDM with less underlying $\beta$-cell dysfunction and therefore less risk to develop T2DM over time. An Irish study showed that of the women who progressed to glucose intolerance postpartum, $90 \%$ had risk factors for GDM $(32,35)$. If health care resources are limited, identifying GDM by using easy-to-use clinical risk factors, might be a good alternative to universal screening to identify the highest risk women for adverse pregnancy outcomes and for glucose intolerance on the long term. 
Strengths of our study are the large multi-ethnic cohort and the fact that clinical risk factors were prospectively collected in early pregnancy. In addition, we evaluated the performance of selective screening across many different guidelines and risk factors. However, some bias in recruitment cannot be excluded since we had less women from an non-Caucasian origin compared to the background population. On the other hand, the rates of overweight and obese women in our cohort were representative of our background population (14). In addition, caution is required to interpret the different analyses in pregnancy outcomes between the different GDM groups and NGT women. Due to the small sample size, the power is limited to evaluate less frequent pregnancy complications such as preeclampsia and preterm delivery.

In conclusion, we show that by applying selective screening by most European guidelines, about $50 \%$ of women would need an OGTT with the lowest number of missed cases (33\%) by the Dutch guidelines. In addition, we demonstrate that a simple approach of offering an OGTT to women $\geq 30$ years and/or with a BMI $\geq 25 \mathrm{~kg}$ / $\mathrm{m}^{2}$ might be a good alternative to more complex risk prediction models and guidelines to screen for GDM. We also demonstrate that despite treatment, GDM women without risk factors had higher rates of neonatal hypoglycemia than NGT women. However, GDM women with risk factors have worse pregnancy outcomes.

\section{Declaration of interest}

The authors declare that there is no conflict of interest that could be perceived as prejudicing the impartiality of this study.

\section{Funding}

This investigator-initiated study was funded by the Belgian National Lottery, the Fund of Academic studies of UZ Leuven and the Fund Yvonne and Jacques François - de Meurs of the King Boudewijn Foundation. The sponsors of the study had no role in the design of the study; or in the collection, handling, analysis; or interpretation of the data or in the decision to write and submit the manuscript for publication.

\section{Author contribution statement}

K B, P V C and C M conceived the project. Carolien Moyson prepared the data and $A$ Laenen did the statistical analysis. $\mathrm{K} B$ did the literature review. $\mathrm{KB}$ and $\mathrm{CM}$ wrote the first draft of the manuscript. All authors contributed to the study design, including data collection, data interpretation and manuscript revision. The corresponding author $\mathrm{K} \mathrm{B}$ had full access to all the data in the study and had final responsibility for the contents of the article and the decision to submit for publication.

\section{Acknowledgements}

$\mathrm{R} D$ is the recipient of a 'Fundamenteel Klinisch Navorserschap FWO Vlaanderen'. The authors thank Dr Inge Beckstedde from the UZA site and
Dr Sylva Van Imschoot from the AZ St Jan Brugge site for their help with the recruitment and study assessments. They thank the research assistants, paramedics and physicians of all participating centers for their support and they thank all women who participated in the study.

\section{References}

1 American Diabetes Association. 14. Management of diabetes in pregnancy: standards of medical care in Diabetes-2019. Diabetes Care 201942 (Supplement 1) S165-S172. (https://doi.org/10.2337/ dc19-S014)

2 Crowther CA, Hiller JE, Moss JR, McPhee AJ, Jeffries WS, Robinson JS \& Australian Carbohydrate Intolerance Study in Pregnant Women (ACHOIS) Trial Group. Effect of treatment of gestational diabetes mellitus on pregnancy outcomes. New England Journal of Medicine 2005352 2477-2486. (https://doi.org/10.1056/NEJMoa042973)

3 Landon MB, Spong CY, Thom E, Carpenter MW, Ramin SM, Casey B, Wapner RJ, Varner MW, Rouse DJ, Thorp JM Jr et al. A multicenter, randomized trial of treatment for mild gestational diabetes. New England Journal of Medicine 2009361 1339-1348. (https://doi. org/10.1056/NEJMoa0902430)

4 Bellamy L, Casas JP, Hingorani AD \& Williams D. Type 2 diabetes mellitus after gestational diabetes: a systematic review and metaanalysis. Lancet 2009373 1773-1779. (https://doi.org/10.1016/ S0140-6736(09)60731-5)

5 Grunnet LG, Hansen S, Hjort L, Madsen CM, Kampmann FB, Thuesen ACB, Granstrømi C, Strøm M, Maslova E, Frikke-Schmidt R et al. Adiposity, dysmetabolic traits, and earlier onset of female puberty in adolescent offspring of women with gestational diabetes mellitus: a clinical study within the Danish national birth cohort. Diabetes Care 201740 1746-1755. (https://doi.org/10.2337/dc17-0514)

6 Consensus P, Metzger BE, Gabbe SG, Persson B, Buchanan TA, Catalano PA, Damm P, Dyer AR, Leiva Ad HM, Kitzmiler JL et al. International association of diabetes and pregnancy study groups recommendations on the diagnosis and classification of hyperglycemia in pregnancy. Diabetes Care 201033 676-682. (https://doi.org/10.2337/dc09-1848)

7 Diagnostic criteria and classification of hyperglycaemia first detected in pregnancy: a World Health Organization Guideline. Diabetes Research and Clinical Practice 2014103 341-363. (https://doi. org/10.1016/j.diabres.2013.10.012)

8 Benhalima K, Mathieu C, Damm P, Van Assche A, Devlieger R, Desoye G, Corcoy R, Mahmood T, Nizard J, Savona-Ventura C et al. A proposal for the use of uniform diagnostic criteria for gestational diabetes in Europe: an opinion paper by the European Board \& College of Obstetrics and Gynaecology (EBCOG). Diabetologia 2015 58 1422-1429. (https://doi.org/10.1007/s00125-015-3615-7)

9 Ryan EA. Diagnosing gestational diabetes. Diabetologia 201154 480-486. (https://doi.org/10.1007/s00125-010-2005-4)

10 Cundy T, Ackermann E \& Ryan EA. Gestational diabetes: new criteria may triple the prevalence but effect on outcomes is unclear. BMJ 2014348 g1567. (https://doi.org/10.1136/bmj.g1567)

11 Benhalima K, Mathieu C, Van Assche A, Damm P, Devlieger R, Mahmood T \& Dunne F. Survey by the European Board and College of Obstetrics and Gynaecology on screening for gestational diabetes in Europe. European Journal of Obstetrics, Gynecology, and Reproductive Biology 2016201 197-202. (https://doi.org/10.1016/j. ejogrb.2016.04.003)

12 Benhalima K, Van Crombrugge P, Verhaeghe J, Vandeginste S, Verlaenen H, Vercammen C, Dufraimont E, De Block C, Jacquemyn Y, Mekahli F et al. The Belgian Diabetes in Pregnancy Study (BEDIP-N), a multi-centric prospective cohort study on screening for diabetes in pregnancy and gestational diabetes: methodology and design. BMC Pregnancy and Childbirth 201414226. (https://doi.org/10.1186/1471-2393-14-226) 
13 Benhalima K, Van Crombrugge P, Moyson C, Verhaeghe J, Vandeginste S, Verlaenen H, Vercammen C, Maes T, Dufraimont E, De Block C et al. The sensitivity and specificity of the glucose challenge test in a universal two-step screening strategy for gestational diabetes mellitus using the 2013 World Health Organization criteria. Diabetes Care 201841 e111-e112. (https://doi. org/10.2337/dc18-0556)

14 Benhalima K, Van Crombrugge P, Moyson C, Verhaeghe J, Vandeginste S, Verlaenen H, Vercammen C, Maes T, Dufraimont E, De Block C et al. A modified two-step screening strategy for gestational diabetes mellitus based on the 2013 WHO criteria by combining the glucose challenge test and clinical risk factors. Journal of Clinical Medicine 20187 E351. (https://doi.org/10.3390/ jcm7100351)

15 American Diabetes Association. Standards of medical care in diabetes - 2013. Diabetes Care 201336 (Supplement 1) S11-S66. (https://doi. org/10.2337/dc13-S011)

16 Devlieger H, Martens G, Bekaert A \& Eeckels R. Standaarden van geboortegewicht-voor-zwangerschapsduur voor de Vlaamse boreling. Tijdschrift voor Geneeskunde 200056 1-14. (https://doi.org/10.2143/ TVG.56.1.5000625).

17 NICE guideline. Diabetes in pregnancy: management from preconception to the postnatal period, 2015. (available at: https:// www.nice.org.uk/guidance/ng3/resources/diabetes-in-pregnancymanagement-from-preconception-to-the-postnatal-periodpdf-51038446021). Accessed on February 2018.

18 Health Service Executive of Ireland. Guidelines for the management of pre-gestational and gestational diabetes mellitus from preconception to the postnatal period, 2010. (available at: http://www. hse.ie/eng/services/Publications/corporate/NursingMidwifery $\% 20$ Services/onsdguidelinesgestationaldiabetes.pdf). Accessed on February 2018.

19 Le Collège national des gynécologues et obstétriciens français et par la Société francophone du diabète. Recommendations pour la pratique clinique: le diabète gestationnel, 2010. (available at: http:// www.cngof.asso.fr/D_TELE/RPC_DIABETE_2010.pdf). Accessed on February 2018.

20 Richtlijn van de Nederlands Vereniging voor Obstetrie en Gynaecologie (NVOG) diabetes mellitus en zwangerschap, 2010. (available at: http://nvogdocumenten.nl/index.php?pagina=/site/ pagina.php\&id=54321). Accessed on February 2018.

21 American Diabetes Association. Diagnosis and classification of diabetes mellitus. Diabetes Care 200932 (Supplement 1) S62-S67. (https://doi.org/10.2337/dc09-S062)

22 Benhalima K, Damm P, Van Assche A, Mathieu C, Devlieger R, Mahmood T \& Dunne F. Screening for gestational diabetes in Europe: where do we stand and how to move forward? A scientific paper commissioned by the European Board and College of Obstetrics and Gynaecology (EBCOG). European Journal of Obstetrics, Gynecology, and Reproductive Biology 2016201 192-196. (https://doi.org/10.1016/j. ejogrb.2016.04.002)

23 Cosson E, Benbara A, Pharisien I, Nguyen MT, Revaux A, Lormeau B, Sandre-Banon D, Assad N, Pillegand C, Valensi P et al. Diagnostic and prognostic performances over 9 years of a selective screening strategy for gestational diabetes mellitus in a cohort of 18,775 subjects. Diabetes Care 201336 598-603. (https://doi.org/10.2337/dc12-1428)
24 Cosson E, Cussac-Pillegand C, Benbara A, Pharisien I, Jaber Y, Banu I, Nguyen MT, Valensi P \& Carbillon L. The diagnostic and prognostic performance of a selective screening strategy for gestational diabetes mellitus according to ethnicity in Europe. Journal of Clinical Endocrinology and Metabolism 201499 996-1005. (https://doi. org/10.1210/jc.2013-3383)

25 Benhalima K, Devlieger R \& Van Assche A. Screening and management of gestational diabetes. Best Practice and Research: Clinical Obstetrics and Gynaecology 201529 339-349. (https://doi. org/10.1016/j.bpobgyn.2014.07.026)

26 Avalos GE, Owens LA, Dunne F \& ATLANTIC DIP Collaborators. Applying current screening tools for gestational diabetes mellitus to a European population: is it time for change? Diabetes Care 201336 3040-3044. (https://doi.org/10.2337/dc12-2669)

27 Farrar D, Simmonds M, Bryant M, Lawlor DA, Dunne F, Tuffnell D $\&$ Sheldon TA. Risk factor screening to identify women requiring oral glucose tolerance testing to diagnose gestational diabetes: a systematic review and meta-analysis and analysis of two pregnancy cohorts. PLoS ONE 201712 e0175288. (https://doi.org/10.1371/ journal.pone.0175288)

28 Naylor CD, Sermer M, Chen E \& Farine D. Selective screening for gestational diabetes mellitus. Toronto Trihospital Gestational Diabetes Project Investigators. New England Journal of Medicine 1997 337 1591-1596. (https://doi.org/10.1056/NEJM199711273372204)

29 Moses RG, Moses J \& Davis WS. Gestational diabetes: do lean young Caucasian women need to be tested? Diabetes Care 199821 1803-1806. (https://doi.org/10.2337/diacare.21.11.1803)

30 Weeks JW, Major CA, de Veciana M \& Morgan MA. Gestational diabetes: does the presence of risk factors influence perinatal outcome? American Journal of Obstetrics and Gynecology 1994171 1003-1007. (https://doi.org/10.1016/0002-9378(94)90023-X)

31 Song C, Lyu Y, Li C, Liu P, Li J, Ma RC \& Yang X. Long-term risk of diabetes in women at varying durations after gestational diabetes: a systematic review and meta-analysis with more than 2 million women. Obesity Reviews 201819 421-429. (https://doi.org/10.1111/ obr.12645)

32 Noctor E, Crowe C, Carmody LA, Avalos GM, Kirwan B, Infanti JJ, O'Dea A, Gillespie P, Newell J, McGuire B et al. Atlantic DIP: simplifying the follow-up of women with previous gestational diabetes. European Journal of Endocrinology 2013169 681-687. (https://doi.org/10.1530/EJE-13-0491)

33 Noctor E, Crowe C, Carmody LA, Saunders JA, Kirwan B, O'Dea A, Gillespie P, Glynn LG, McGuire BE, O’Neill C et al. Abnormal glucose tolerance post-gestational diabetes mellitus as defined by the International Association of Diabetes and Pregnancy Study Groups criteria. European Journal of Endocrinology 2016175 287-297. (https:// doi.org/10.1530/EJE-15-1260)

34 Benhalima K, Jegers K, Devlieger R, Verhaeghe J \& Mathieu C. Glucose intolerance after a recent history of gestational diabetes based on the 2013 WHO criteria. PLOS ONE 201611 e0157272. (https://doi.org/10.1371/journal.pone.0157272)

35 O'Reilly MW, Avalos G, Dennedy MC, O'Sullivan EP \& Dunne F. Atlantic DIP: high prevalence of abnormal glucose tolerance post partum is reduced by breast-feeding in women with prior gestational diabetes mellitus. European Journal of Endocrinology 2011165 953-959. (https://doi.org/10.1530/EJE-11-0663)
Received 21 February 2019

Revised version received 4 April 2019

Accepted 11 April 2019 